\title{
Errata for Xiang et al., Effect of sludge amino acid-modified magnetic coal gasification slag on plant growth, metal availability, and soil enzyme activity
}

Volume 75(4), p. 518:Table 2 should appear as follows:

\section{Table 2}

Physicochemical properties of mine soil (MS) and artificial soil (AS) with soil amendments (sludge amino acids [SAA], magnetic coal gasification slag [MCGS], and amino acid-modified magnetic coal gasification slag [AMS]) before planting.

\begin{tabular}{|c|c|c|c|c|c|c|c|c|c|c|c|}
\hline Item & & pH & $\begin{array}{l}\text { CEC } \\
\left(\mathrm{cmol} \mathrm{kg}^{-1}\right)\end{array}$ & $\begin{array}{l}\mathrm{CaCO}_{3} \\
\left(\mathrm{~g} \mathrm{~kg}^{-1}\right)\end{array}$ & $\begin{array}{l}\text { MC } \\
(\%)\end{array}$ & $\begin{array}{l}\text { Total N } \\
\left(\mathrm{g} \mathrm{kg}^{-1}\right)\end{array}$ & $\begin{array}{l}\text { Total P } \\
\left(\mathrm{g} \mathrm{kg}^{-1}\right)\end{array}$ & $\begin{array}{l}\text { Total K } \\
\left(\mathrm{g} \mathrm{kg}^{-1}\right)\end{array}$ & $\begin{array}{l}\text { Available N } \\
\left(\mathrm{mg} \mathrm{kg}^{-1}\right)\end{array}$ & $\begin{array}{l}\text { Available P } \\
\left(\mathrm{mg} \mathrm{kg}^{-1}\right)\end{array}$ & $\begin{array}{l}\text { Available K } \\
\left(\mathrm{mg} \mathrm{kg}^{-1}\right)\end{array}$ \\
\hline MS & & $7.54 a$ & $7.80 c$ & $108.21 a$ & $4.02 \mathrm{c}$ & $0.73 b$ & $0.42 b$ & $14.13 c$ & $2.34 b$ & $3.21 b$ & $99.86 a$ \\
\hline \multirow[t]{2}{*}{$\left(w^{-1}\right)$} & $5 \%$ & $7.42 b$ & $12.69 b$ & $101.06 b$ & $8.26 b$ & $1.78 \mathrm{a}$ & $0.42 b$ & $60.71 a$ & $3.23 a$ & $4.31 \mathrm{a}$ & $99.65 b$ \\
\hline & $10 \%$ & $7.41 b$ & $14.78 a$ & $98.19 b$ & $12.15 a$ & $2.32 a$ & $0.40 \mathrm{~b}$ & $63.11 a$ & $3.22 a$ & $5.42 a$ & $99.95 a$ \\
\hline$\left(w w^{-1}\right)$ & $10 \%$ & $7.69 a$ & $17.98 a$ & $112.22 \mathrm{a}$ & $12.98 a$ & $1.09 a$ & $0.42 b$ & $57.87 a b$ & $3.22 a$ & $3.98 a$ & $100.78 b$ \\
\hline AS with AMS & $1 \%$ & $7.51 a$ & $11.43 a$ & $108.89 a$ & $6.87 \mathrm{~b}$ & $0.98 b$ & $0.41 b$ & $56.10 a b$ & $3.21 a$ & $3.66 a$ & $99.98 a$ \\
\hline \multirow[t]{2}{*}{$\left(w^{-1}\right)$} & $5 \%$ & $7.49 a$ & $15.77 a$ & $109.02 a$ & $9.49 a b$ & $1.41 \mathrm{a}$ & $0.40 b$ & $59.23 a$ & $3.18 a$ & $4.02 a$ & $100.06 a$ \\
\hline & $10 \%$ & $7.47 a$ & $18.01 a$ & $109.54 a b$ & $13.75 a$ & $1.82 \mathrm{a}$ & $0.43 b$ & $61.12 a$ & $3.20 a$ & $4.75 a$ & $100.34 a$ \\
\hline
\end{tabular}

Notes: $\mathrm{CEC}=$ cation exchange capacity. $\mathrm{CaCO}_{3}=$ calcium carbonate. $\mathrm{MC}=$ moisture content. $\mathrm{N}=$ nitrogen. $\mathrm{P}=$ phosphorus. $\mathrm{K}=$ potassium. Each value is based on dry weight. Different letters in the same column are significantly different $(p<0.05)$.

Volume 75(4), p. 522: Column 2, Lines 15-16 should read as follows: "There seemed to be many more small particles in figure 6c than in 6a." 
Volume 75(4), p. 524: Figure 8 should appear as follows:

\section{Figure 8}

Predicted mechanism of amino acid-modified magnetic coal gasification slag (AMS) and Alhagi sparsifolia repair mining area.

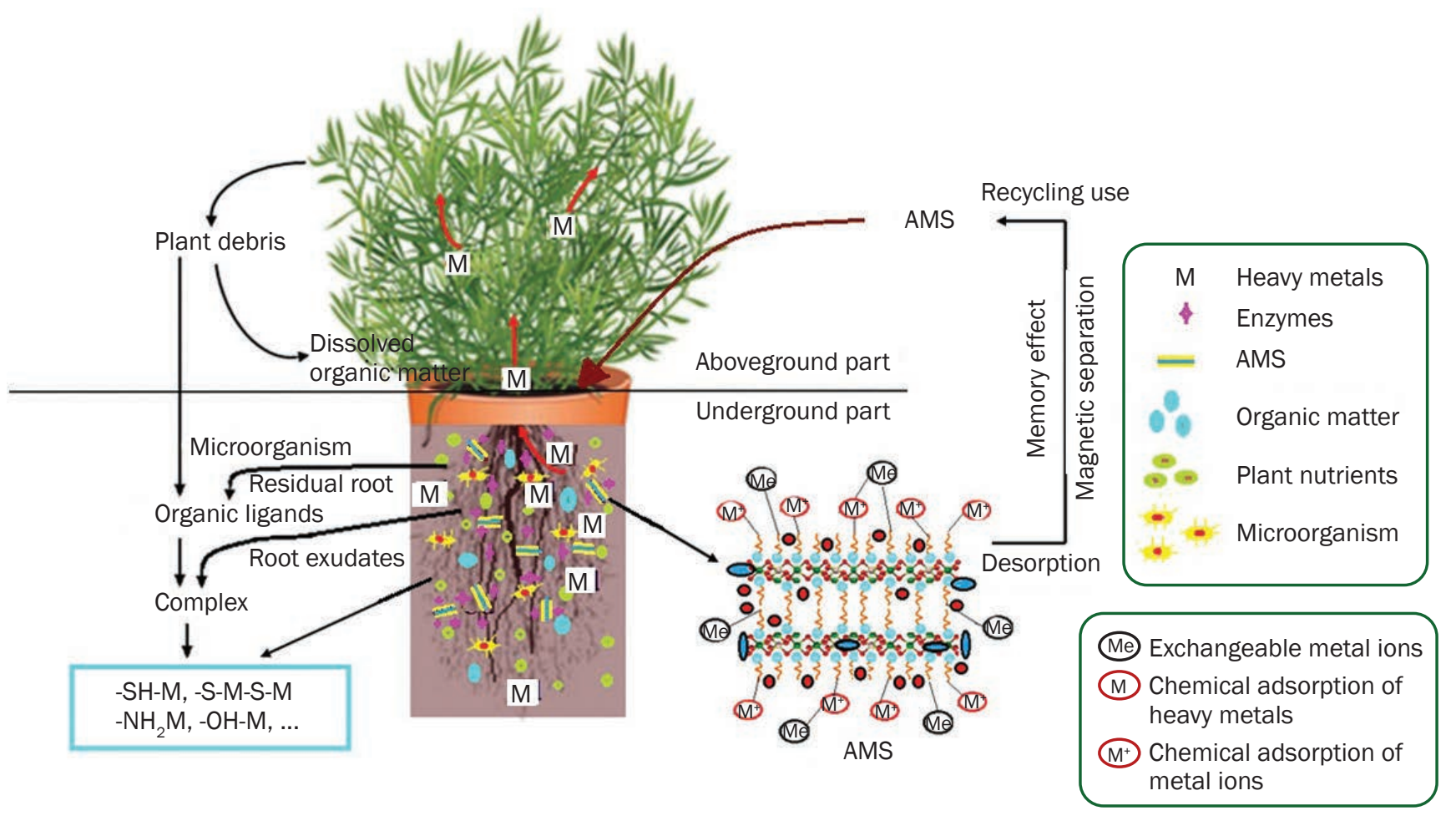

\section{Reference}

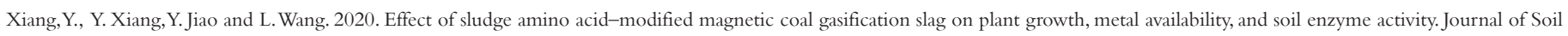
and Water Conservation 75(4):515-526, DOI: https://doi.org/10.2489/jswc.2020.00088. 